\title{
Do vulnerabilities to radiofrequencies vary according to age? Different physiology, different vulnerabilities
}

\author{
Mary Redmayne
}

Environment and Earth Sciences, School of Geography, Victoria University of Wellington, PO Box 600, Wellington, New Zealand

ARTICLE INFO

* Correspondence to:

Mary Redmayne

Environment and Earth Sciences,

School of Geography,

Victoria University of Wellington,

Wellington, New Zealand

e-mail:mary.redmayne@gmail.com

\section{Keywords:}

Brain

Electromagnetic field

Oxidative stress

Melatonin levels

\section{ABSTRACT}

The difference in responses of the young, healthy adults, and the elderly to radiofrequencies (RF) exposure are more numerous and complex than those generally preffered. This presention explores some relevant changes that occur physiologically through the lifespan. These include a brief description of the development of the central nervous system, myelin sheathing, alpha and delta brain activity, oxidative stress and melatonin levels, pinna and skull thickness, dielectric tissue values, water and ions in tissues, and resonance. It will then review research indicating age-dependent effects from RF exposure and discuss implications where age-dependent research findings are not available.

J. Exp.Clin.Med., 2013; 30: 268 